\title{
The Ties That Bind Olga Alexandrovna Ladyzhenskaya and the 2022 ICM in St. Petersburg
}

\section{Della Dumbaugh, Panagiota Daskalopoulos, Anatoly Vershik, Lev Kapitanski, Nicolai Reshetikhin, Darya Apushkinskaya, and Alexander Nazarov}

\section{Della Dumbaugh}

When the International Congress of Mathematicians (ICM) convenes in St. Petersburg in 2022, it will not only bring together mathematicians from all corners of the globe but it will also provide an appropriate opportunity to celebrate the 100th anniversary of the birth of Olga Alexandrovna Ladyzhenskaya. A Russian mathematician who overcame tremendous personal tragedy, Ladyzhenskaya built a legacy through her work in partial differential equations and her interactions with students, colleagues, and collaborators during a challenging time in Soviet history. This meaningful confluence of events is celebrated on the pages of the first issue of the ICM News with a collection of essays "written by renowned experts, people who either knew her well or who were influenced by her in a transformative way." Here, we reprint those essays with this brief introduction to the life of Ladyzhenskaya.

Born in 1922 in the tiny town of Kologriv, a picturesque area located about 300 miles northeast of Moscow, Ladyzhenskaya began learning mathematics from her father in the summer of 1930. A math and art teacher at the local high school, Aleksandr Ivanovich Ladyzhensky had descended from Russian nobility. After explaining the fundamental principles of geometry to Olga and her two sisters, he would formulate a theorem and ask his daughters to prove it themselves. This environment allowed Olga's

Della Dumbaugh is a professor of mathematics at the University of Richmond and an associate editor of the Notices. Her email address is ddumbaugh@richmond.edu.

For permission to reprint this article, please contact: reprint-permission aams.org.

DOI: https://dx.doi.org/10.1090/noti 2047 mathematical skills to come to the fore [Friedlander et al., p. 1322]. Despite the remote location of their home, Olga and her sisters also gained a rich cultural awareness of the world through the family's extensive collection of books. Her great uncle, Gennady Ladyzhensky, was one of Russia's celebrated water colorists. Olga maintained a lifelong interest in literature and the arts, perhaps cultivated early on by these childhood influences.

In 1937, after advocating for his students whose parents had been arrested by the NKVD (the predecessor of the KGB), Olga's father was arrested and executed without trial. She was sixteen years old at the time. Although the family struggled to survive after her father's disappearance and death, Olga finished high school in 1939 with high marks. Now classified as a daughter of an "enemy of the people," however, Olga was forbidden to enroll at Leningrad State University. ${ }^{1}$ She was, however, permitted to study at Pokrovski Teachers' Training College in what was then Leningrad. During the war, Olga initially moved to Gorodets to teach at an orphanage and then returned to Kologriv to teach at the high school she had attended and at which her father had taught. Continuing her father's commitment to students, she taught anyone interested in mathematics with no compensation required or expected. This good deed ultimately led to an opportunity for her to study mathematics at Moscow State University when the mother of one of her students intervened on her behalf.

In Moscow, she began her mathematics training with algebra and number theory and, later, turned her attention

\footnotetext{
${ }^{1}$ St. Petersburg State University was founded in 1724 by Peter the Great. During the Soviet period from 1922 to 1991, the institution was known as Leningrad University.
} 


\section{HISTORY}

to differential equations. She was awarded a Stalin stipend (the irony) and a ration card, both of which allowed her to survive as a student. Even still, she was often hungry during her time in Moscow and she sometimes slept on benches in the auditorium with her books as a pillow. She would later describe this sleeping arrangement as an opportunity to learn by osmosis [Daskalopoulos et al., p. 12].

Her interest in partial differential equations grew out of the influence of Ivan Petrovsky and the second volume of Methods of Mathematical Physics by Courant and Hilbert, which focused on partial differential equations. ${ }^{2}$ After she graduated from Moscow State University in 1947, she moved to Leningrad where she not only began graduate school but also a longstanding friendship with Vladimir Smirnov. She completed her thesis in 1951, with Sergei Sobolev serving as the official advisor and Smirnov as the advisor who actually oversaw her work on linear and quasilinear hyperbolic systems of partial differential equations. She published her first book in 1953. She would go on to publish six more monographs, some as long as 700 pages, along with more than 250 papers. In 1947, Olga and Smirnov also started and co-led a weekly seminar on mathematical physics that became known as the "Smirnov Seminar." She continued to run the seminar after his death in 1974, and it still meets today. In his reflections below, Lev Kapitanski chronicles the importance of this seminar in his training. In particular, he notes that Olga would "often ask questions, sometimes very basic, and these would be the most revealing, the most teachable moments" [Daskalopoulos et al., p. 12].

Ladyzhenskaya and her collaborators, including her students, extended the ideas of Ennio De Giorgi and John Nash to offer a complete solution to Hilbert's nineteenth problem on the regularity of solutions of elliptic partial differential equations. She began working in fluid dynamics in the mid-1950s and published her influential text The Mathematical Theory of Viscous Incompressible Flow in 1961. She was particularly interested in the Navier-Stokes equations. She taught mathematics throughout her life and, despite the

\footnotetext{
${ }^{2}$ In his 1938 review of this Courant-Hilbert volume for the Bulletin of the American Mathematical Society, Hermann Weyl called attention to the political influences at play in its creation when he wrote, "[t]he two volumes are a beautiful, lasting, and impressive monument of what Courant, inspired by the example of his great teacher Hilbert and supported by numerous talented pupils, accomplished in Göttingen, both in research and advanced instruction. Courant came to Göttingen at a time of enormous political and economic difficulties for Germany, on a difficult inheritance, with the day of the heroes, Klein, Hubert, and Minkowski drawing to a close. But by research and teaching, by personal contacts, and by creating and administering in an exemplary manner the new Mathematical Institute, he did all that was humanly possible to propagate and develop Göttingen's old mathematical tradition. How his fatherland rewarded him is a known story. The publication of the present volume seems to the reviewer a fitting occasion for expressing the recognition his work has earned him in the rest of the mathematical world" [Weyl, p. 602].
}

tragedy of her father's death, she remained patriotic. In particular, she encouraged Russian mathematicians to remain in Russia.

She received a number of awards and honors in her lifetime, including the State Prize of the USSR in 1969 and the Great Gold Lom onosov Medal of the Russian Academy in 2002.

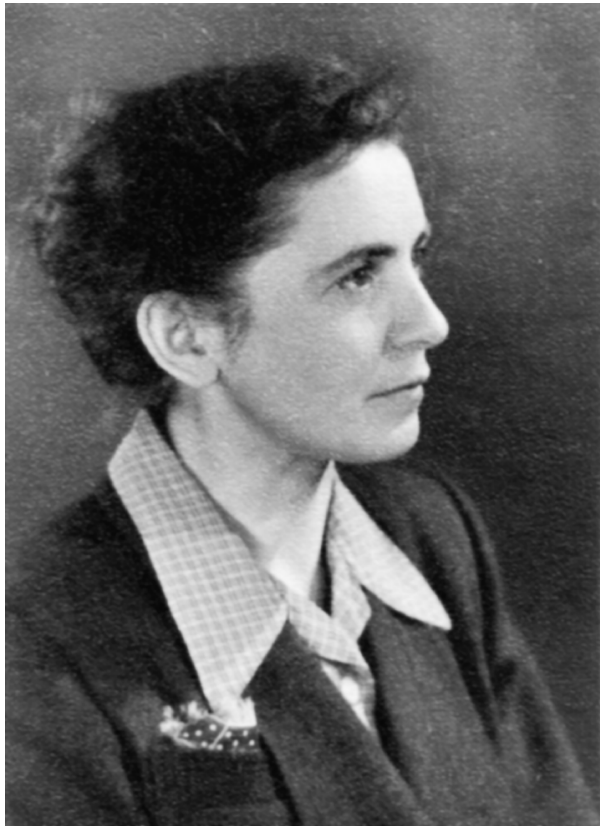

Figure 1. Olga Alexandrovna Ladyzhenskaya in 1959.
Ladyzhenskaya is also featured in an exhibition in the Science Museum of Boston. There, "the names of the most influential mathematicians of the 20th century are carved on a large marble desk... and Olga Ladyzhenskaya is among them" [Friedlander et al., p. 1321].

Even more, however, Ladyzhenskaya was a beloved human being. " $[\mathrm{H}]$ er personal integrity and energy played an especial role in her contribution to mathematics" [Friedlander et al., 1321]. She cared deeply for others, especially those who suffered injustices. She loved the arts, travel, and the outdoors. She was unafraid to express her viewpoint, even in the face of a dangerous political climate. She died in 2004.

Although Ladyzhenskaya is often compared with Sofia Kovalevskaya, this timely opportunity to link her life with the 2022 ICM provides an occasion to look more broadly for shared connections with the lives of other mathematicians worldwide. Her vast output of mathematics, for example, calls to mind the American Leonard Dickson's monumental publication record in algebra and number theory. Her patriotism for Russia is reminiscent of Hua Luogeng's for China. Her love of travel and her vibrant energy that inspired contributions to mathematics until the last days of her life share an uncanny similarity with the Russian-born, French-raised, and American-engineer-turned-topologist Solomon Lefschetz. Her life born out of faith, including her concern for the less fortunate and her teaching of children at an orphanage and in her small hometown, share a common thread with the American statistician Gertrude Cox. Thus when the ICM convenes in St. Petersburg in 2022 , it will not only celebrate the centennial birthday of 
Olga Ladyzhenskaya and the mathematics of today, but it will also honor a rich continuum of mathematics and the ties that bind mathematicians together.

\section{References}

Panagiota Daskalopoulos et al., Olga Alexandrovna Ladyzhenskaya, ICM News, First Issue. math.columbia.edu /\%7Eokounkov/Ladyzhenskaya.pdf

Susan Friedlander et al., Olga Alexandrovna Ladyzhenskaya (1922-2004), Notices Amer. Math. Soc. 51 (December 2004), no. 11, 1320-1331. MR2105237

Max Gunzburger, Olga Ladyzhenskaya, SIAM News 37 (April 2004), no. 3. https://archive.siam.org/pdf/news/209 .$p d f$

Hermann Weyl, Book Review: Methoden der mathematischen Physik, Bull. Amer. Math. Soc. 44 (1938), no. 9, 602-604. MR1563804

\section{Panagiota Daskalopoulos}

As a high-school student in Greece with a passion for mathematics, I was fascinated by the life and achievements of the Russian mathematician Sofia Kovalevskaya. My fascination was not limited to her deep contributions in analysis and partial differential equations, but included her inspiring life, which showed her continuous courage in overcoming all obstacles in order to pursue what she loved: mathematics.

It was a few years later, during my graduate school days at the University of Chicago, that I became aware of another great Russian female mathematician of remarkable intellect and courage: Olga Aleksandrovna Ladyzhenskaya, one of the leading figures in the development of partial differential equations in the 20th century. I was given a thesis problem related to quasilinear parabolic equations and needed to study Olga Ladyzhenskaya's monograph, written with her students Nina Uraltseva and Vsevolod Solonnikov, on linear and quasilinear equations of parabolic type. This monograph of more than 700 pages, published in Russian in 1967, contains important, mostly original work by the authors on the solvability and regularity of parabolic quasilinear equations of second order. Previous fundamental works by Olga Ladyzhenskaya with Nina Uraltseva on elliptic quasilinear equations of second order were the subject of an earlier monograph, published in Russian in 1964. Both monographs were later translated into English by the American Mathematical Society. Many of us have learned a lot from her two great books, which were the best source on elliptic and parabolic partial differential equations available before the more recent books of GilbargTrudinger and Lieberman. Many of the results in these two monographs are still very relevant today.

Olga Ladyzhenskaya started working on second order elliptic boundary-value problems shortly after her thesis,

Panagiota Daskalopoulos is a professor of mathematics at Columbia University. Her email address is pdaska1o@math. columbia. edu. which she defended in 1949 and which was supervised by the famous analyst Sergei Lvovich Sobolev. In 1951, shortly after her thesis, she proved one of the most fundamental inequalities for second order elliptic operators $\mathcal{L}$ with smooth coefficients, which states that any function $u \in W^{2,2}(\Omega)$ satisfying one of the homogeneous classical conditions on the boundary of the smooth domain $\Omega$ satisfies the inequality

$$
\|u\|_{W^{2,2}(\Omega)} \leq C(\Omega)\left(\|\mathcal{L} u\|_{L^{2}(\Omega)}+\|u\|_{L^{2}(\Omega)}\right) .
$$

This inequality has had a tremendous impact in the development of second-order PDE, and it is now contained in any graduate text on the subject.

The 1950s was an exciting time for the development of elliptic PDEs. Following S. N. Bernstein's approach based on a priori estimates for solutions, the fundamental works by Leray and Schauder had reduced the classical solvability of the Dirichlet problem to obtaining a priori estimates of the solutions in $C^{1, \alpha}$ norm. However, up to the mid-1950s most of the important results were in two dimensions and often under rather restrictive conditions. It was around that time that the works by E. De Giorgi and by J. Nash on Hölder regularity of solutions to linear parabolic and elliptic equations in divergence form with bounded measurable coefficients came out. These results were to change the field forever, and Ladyzhenskaya played a leading role in this transformation. In a number of important works with her students N. Uraltseva and later with V. Solonnikov in the parabolic setting, she contributed many deep results in the study of boundary-value problems for quasilinear elliptic and parabolic equations. They developed a complete theory for the solvability and regularity of boundary-value problems for elliptic and parabolic equations in divergence form, greatly extending the techniques of De Giorgi, Nash, and Moser. These results, which were included in her two monographs mentioned above, remained at the forefront of the field for many years. It was only much later, in the early 1980s, that the celebrated Krylov-Safonov Hölder regularity result for solutions of elliptic and parabolic equations in non-divergence form led to an equally complete theory for equations in non-divergence form and opened new exciting directions in the development of fully nonlinear PDEs.

In the mid 1950s Olga Ladyzhenskaya started working in fluid mechanics. She became interested in the Navier-Stokes equations, a system of equations that is known for its intriguing complexity despite its very simple form. Only a few years after Olga Ladyzhenskaya entered the field she established a breakthrough: her 1959 result on the global unique solvability of the initial boundary value problem for the 2D Navier-Stokes equations in domains with boundary. She continued making important contributions in this area during the rest of her career. 
J. Leray, in his seminal work from 1934, established the global unique solvability for the Cauchy problem for the Navier-Stokes equations in dimension two. However, for more than 20 years after Leray's work, the global unique solvability of the 2D Navier-Stokes equations on domains with boundary has been an open question. In domains without boundary, to which Leray's methods apply, one has in dimension two an a priori bound for the vorticity, which makes the equation sub-critical, in today's terminology. This bound does not work well near the boundary, and one can work only with the energy estimate, for which the equation is critical in dimension two. In today's terminology, the Navier Stokes equation is critical when considered in domains with boundaries. It was pointed out to the author that Ladyzhenskaya's work proving regularity of the solution in this situation was one of the first where a PDE with a critical nonlinearity was successfully handled. ${ }^{3}$ To solve the problem, Olga Ladyzhenskaya established another fundamental inequality, which now carries her name, namely that for any $u \in C_{0}^{\infty}\left(\mathbb{R}^{2}\right)$, one has

$$
\|u\|_{L^{4}\left(\mathbb{R}^{2}\right)} \leq C\|u\|_{L^{2}\left(\mathbb{R}^{2}\right)}\|\nabla u\|_{L^{2}\left(\mathbb{R}^{2}\right)}
$$

where $C$ is a universal constant. Inequalities of the above type are often referred to as multiplicative inequalities and have been extensively used since then. These and others of her first important results on the Navier-Stokes equations are included in her seminal monograph titled Mathematical Theory of Viscous Incompressible Flows, which still remains one of the most influential books in the field.

For the three-dimensional system of equations, the global unique solvability of the Navier-Stokes equations is still an open question and one of the Clay Foundation Millennium problems. Despite the continuous effort of many great mathematicians, there is still much to be understood about this complex problem. Since very early on, there has been a continuous debate as to whether the initial value problem in three dimensions admits a smooth solution for all time, and, if not, whether a generalized solution is uniquely determined by the initial data. Olga Ladyzhenskaya stayed at the forefront of this discussion, contributing a continuous flow of ideas. She seemed to believe that the class of Leray-Hopf solutions of the NavierStokes equations is so weak that one cannot expect that uniqueness holds in this class. As a result, she proposed a model of "modified Navier-Stokes equations," and she proved unique global solvability for this system. Her model, which only differs from the original model in regions where the velocity fluctuates rapidly, was presented at the International Congress of Mathematicians in Moscow in 1966. It is now called the "Ladyzhenskaya model," and it is widely studied. In a work published in 1969, Olga Ladyzhenskaya

\footnotetext{
${ }^{3}$ The author thanks Vladimir Sverak for this comment.
}

constructs an example of non-uniqueness of weak Hopf solutions in a non-standard time-dependent domain. In this work she writes: "As regards the class of weak Hopf solutions for the general three-dimensional case, it has always seemed to me that it is too broad, i.e., that there is missing in it a basic property of the initial-value problem, viz. its determinacy (a uniqueness theorem) .... But I had available only indirect reasons in support of this assertion .... which had no formal demonstrative power. At this time I am able to rigorously prove the validity of my opinions."

Some of the late results by Ladyzhenskaya concern attractors to 2D Navier-Stokes and the 3D modified Navier-Stokes equations, as well as to quasilinear parabolic systems. In these works she developed new techniques that are now widely used in many other situations.

There is so much more that could be said about the mathematics of Olga Ladyzhenskaya and about her great influence on the developments in partial differential equations and mathematical physics in the 20th century. Besides her own research, her constant flow of ideas, support, and encouragement towards her students and other members of her school in St. Petersburg had a tremendous influence on mathematics in the Soviet Union. In one of her last public lectures, at a conference held in Madeira in June 2003, Olga Ladyzhenskaya offered a spirited philosophical take on her ideas on Navier-Stokes equations. It was her spirit, deep and broad intellect, kind supportive character, and courage that made her the distinguished mathematician she was, and an inspiration for all of us.

There has recently been a lot of discussion among mathematicians in academia as to how to increase the influence of women in mathematics. Olga Ladyzhenskaya represents a role model for both the current and the future generations of women in mathematics: deep important work, courage, and a kind, supportive spirit.

\section{Anatoly Vershik}

Olga Alexandrovna (in these notes referred to as O. A., following the Russian convention of abbreviating the first and patronymic names) is without doubt the most intriguing figure in Russian mathematics of the second half of the 20th century. The obvious comparison with another brilliant figure of St. Petersburg and European mathematics, Sofia Vasilievna Kovalevskaya (1850-1891), is a natural and logical one. While the two lived in very different times, and their lives followed two disparate trajectories, many things unite them: the magnitude of their talent; their role in science; both being the best representatives of the Russian intelligentsia, with its interest in poetry, literature, and art; and, finally, a certain aura surrounding both of them. S. V. Kovalevskaya was adored by many luminaries of her

Anatoly Vershik is principal researcher and head of laboratory, St. Petersburg branch of the Mathematical Institute of the Russian Academy of Science. His email address is avershik@gmai 1.com. 
time, K. F. Weierstrass, who could be considered one of her teachers, among them. Similarly, O. A. was adored by her teachers. The latter include I. G. Petrovsky (1901-1973), president of Moscow State University and her teacher in Moscow, as well as S. L. Sobolev (1908-1989) and V. I. Smirnov (1887-1974), both members of the Academy of Sciences, who taught O. A. in St. Petersburg.

Both Kovalevskaya and Ladyzhenskaya studied differential equations, a vast area of mathematics, where well-known theorems are named after them. O. A. is particularly renowned for her achievements in the theory of quasilinear equations and in mathematical hydrodynamics-she proved the solubility and local existence for the Navier-Stokes equations.

And similarly, fate was unmerciful to both. S. V., despite her extraordinary achievements, could not overcome the inertia of the Russian academic bureaucracy and get a professorship in Russia. Hardships in O. A.'s life were of a different nature.

O. A. was born in a small modest Russian townKologriv, not far from Kostroma, some 300 kilometers from Moscow. Her father was a school math teacher, a well-known and respected figure in the community. At the height of Stalin's repressions (1937/8) he advocated on behalf of children whose parents were arrested. As a result, he was himself arrested and shortly after executed. $\mathrm{O}$. A. was sixteen at the time. Many years later, O. A. made a brief documentary about her father-a remarkable Russian intellectual and officer and a connoisseur of poetry and art. Leading universities were off-limits for a daughter of an "enemy of the people," so she applied to a second-rate pedagogical university in Leningrad, where she studied for two years until the advent of the war [in Russia the Second World War began in June of 1941].

During the turbulent years of the war, she managed to conceal this tragedy and to get accepted at Moscow State University. After graduation she was confronted with the problem of landing a job because in Moscow, Russia's "first" capital, people with such CVs could not get a decent research position-these were Stalin's times after all. Fortunately for her, and fortunately for many other people, she was noticed by V. I. Smirnov (1887-1974), who still had some influence at Leningrad University. A patriarch of Leningrad mathematics and an authority in mathematical physics, he immediately recognized her talent. Smirnov combined the old, pre-revolutionary scientific traditions with the best that appeared after the revolution; despite much hardship, he didn't suffer the merciless fate shared by many scientists of the older generation during the Soviet times. A. D. Alexandrov (1912-1999), a noted geometer and later the president of the Leningrad University, became another supporter and an older friend of $\mathrm{O}$. A.

O. A. thrived as a professor in the physics department; her brilliant papers and books are to this day among the citation leaders. She stayed in close contact with Smirnov for the rest of his life; together they ran the famous Mathematical Physics Seminar at the university, which she continued to run after his death. Among her students, $\mathrm{N}$. $\mathrm{N}$. Uraltseva and V. A. Solonnikov are perhaps best known and closest to O. A. in terms of field of study, but she was also the first advisor of L. D. Faddeev (1934-2017) and the one who supervised his first steps in mathematical physics.

Her achievements were internationally and broadly recognized, and her talks enjoyed success; she visited research centers in many countries at a time when for obvious reasons most Soviet mathematicians couldn't travel abroad. Yet, after a certain point, she, too, was not allowed to travel. Let me explain why.

In her sentiments, which she didn't publicize, O. A. was of course always siding with the oppressed, with those suffering from injustice or even persecution, of which there were very many during the Soviet times. The authorities had their suspicions and even information about this, but O. A.'s mathematical accomplishments and prominence curbed their appetite, but only up to a certain point. That point was the meeting between O. A. and A. I. Solzhenitsyn. Smirnov, who had a dacha in Komarovo, a town not far from Leningrad, introduced O. A. to his neighbor Anna Akhmatova and to other prominent authors and artists. When Solzhenitsyn came to visit, Smirnov introduced O. A. to him, as well. O. A. and Solzhenitsyn became friends and she shared with him, in detail, the story of her father's execution. Solzhenitsyn described this episode, keeping the original names, in his monumental Gulag Archipelago. Naturally, being so frank with an enemy of the Soviet regime, an author of banned books, and someone soon to be exiled, could not be endorsed by the authorities. As soon as "Big Brother" learned about this, O. A. was punished by being banned from traveling abroad. This ban was lifted only during the early years of the Perestroika.

While mathematics and science were the primary and principal passions of $\mathrm{O}$. A., she was also fascinated by literature and the arts. She befriended and supported many young Leningrad poets and artists, whom she helped as much as she could. There was always a whirlpool of youth around her, and she was in the very middle of it. She was also athletic - an active traveler and backpacker.

We were friends and we had many mutual friends, outside of mathematics as well. At some time in the 1970s, we worked together on something of interest to both of us and published several joint papers. But her chief research interests were far from mine.

I can always conjure up an image of her constant mathematical activity. A lot of people wanted to talk to her, tell her about their work, and get her involved. But I also had a chance to witness her continuous engagement in life outside of mathematics.

Here is a typical story. There was a group of young authors called "Gorozhane," or townspeople, comprised of four members and one-younger-candidate: S. Dovlatov. 
They were far from the official mainstream and therefore were never published. This group decided to hold a public reading of their short stories. A. Volodin, a well-known author of the older generation, agreed to be the moderator. They were able to find a venue at the House of Cinema ("Dom Kino"), reserved for three hours sharp. They invited young people, young scientists, and also O. A., who knew some members of this group. What followed was typical of those times and of the people involved. At the scheduled time, and it was a Sunday, about sixty to seventy people gathered at the entrance, which was...bolted shut. Obviously, those who gave their permission for the reading became anxious at the last moment about organizing a "questionable" event, but didn't inform anybody of their decision to withdraw the permission.

General confusion, despair, and anger.... Suddenly, the ringing voice of O. A.: "Let's go to the Mathematical Institute! It is very close." One has to appreciate the courage and nontriviality of this proposal. The crowd followed O. A., and the reading successfully took place in the main seminar hall of the Institute. We never had such "seminars" at the Institute either before or after.

\section{Lev Kapitanski and Nicolai Reshetikhin}

You know who the great mathematicians in your field are. All the prizes, positions, titles, etc., tickle vanity and grant official respect, but in the end are irrelevant. Everyone knows who the greats are.

Olga Aleksandrovna Ladyzhenskaya was a great mathematician. The modern shape of her field, partial differential equations, was in large part set by her. From the basic question "What is a solution to the boundary value or the initial boundary value ("mixed") problem?" to the subtle properties of solutions (her "generalized solutions") for elliptic, parabolic, hyperbolic, the Navier-Stokes, and other equations, her masterful brushstrokes, bold and precise, brought new colors and shapes to the canvases of modern PDE theory. Her great-uncle, Gennady Ladyzhensky, the father of Russian watercolor, and her beloved father, Aleksandr Ivanovich Ladyzhensky, a mathematics and art school teacher, ${ }^{4}$ would have been proud of her.

\footnotetext{
Lev Kapitanski is a professor of mathematics at University of Miami. His email address is 1. kapi tanski@mi ami . edu.

Nicolai Reshetikhin is a professor of mathematics at UC Berkeley. His email address is reshetik@math. berkeley. edu.

${ }^{4}$ In 1937, for the coming anniversary of the Great October Revolution, Aleksandr Ivanovich asked the pupils in his art class to paint decorative plates with ornaments made of revolutionary symbols. As an example he showed them his own ornament. In October 1937 Aleksandr Ivanovich was arrested by the NKVD, the precursor of the KGB. The official reason was that in his ornament he had used a hammer and a sickle but in different parts of the plate, not together, which meant nothing less than that he was against the alliance of the working class and peasantry - a capital crime. Shortly after his arrest he was executed. In 1956 he was rehabilitated and exonerated.
}

LK: O. A. told me on several occasions that when she was a student she wanted to study the Einstein equations, but thought she had first to understand the hyperbolic equations and the equations of fluid mechanics, such as the Navier-Stokes equations.

NR: As a graduate student, O. A. studied linear and quasilinear hyperbolic equations and systems. She had chosen to build convergent finite-difference schemes to construct solutions, and stayed with the plan, overcoming technical difficulties as they appeared. In her $\mathrm{PhD}$ thesis (defended in March, 1949), O. A. included her results on the Cauchy problem for general linear and quasilinear hyperbolic systems. But by that time she already knew much more. Amazingly, it was through the finite differences analysis that $\mathrm{O}$. A. established powerful functional analytic methods that she would use for the initial boundary value problems for hyperbolic equations (her Doctor of Physico-Mathematical Sciences degree and the first book Mixed Problems for Hyperbolic Equations, 1953; only in Russian), and then she would move on to resolve the basic problems for elliptic, parabolic, and Schrödinger type equations.

And then more intensive analysis followed for elliptic equations (her book with Uraltseva) and parabolic equations (her book with Solonnikov and Uraltseva), and then the Navier-Stokes equations (her book The Mathematical Theory of Viscous Incompressible Flow, 1961), and then so many new questions were unearthed that needed answers.

O. A. moved to Leningrad (St.-Petersburg) in the fall of 1947. She went to the Mathematics and Mechanics Department of Leningrad State University to inquire about graduate school, and looked around the department, and met a wonderful person, academician Vladimir Ivanovich Smirnov.

LK: The story is that when V. I. Smirnov was nominated for membership at the Academy in 1939, he found out that S. L. Sobolev was the second nominee for the same position, and Smirnov withdrew his candidacy out of respect for Sobolev, and out of innate modesty.

NR: Smirnov was the main force behind rebuilding mathematics departments and reviving the mathematical tradition in Leningrad after WWII. He took O. A. under his wing, and they remained close mathematical and personal friends until his last days. Incidentally, in the fall of 1947 Smirnov started a city seminar on mathematical physics (in Russia, PDEs are considered a large part of mathematical physics). From the beginning, O. A. was a co-chair and an active participant of what became known for generations of mathematicians as the Smirnov Seminar ("Smirnovskiy Seminar").

LK: I started attending the Smirnov Seminar after Smirnov had already passed away. It was a weekly Monday night two-hour (with a ten-minute break) gathering of mathematicians in the general area of mathematical physics. O. A. was usually sitting in the front row together 
with Nina Nikolaevna Uraltseva, Mikhail Solomonovich Birman, and a few other renowned mathematicians. O. A. would invite speakers from all directions of mathematical physics, PDEs, spectral theory, analysis, topology. (V. A. Rokhlin gave a talk (his last) at the Smirnov Seminar shortly before he passed away.) In addition, O. A. ran a weekly research seminar (also two hours in duration) at the Laboratory of Mathematical Physics at LOMI. Those two seminars were my school. All new results and new trends were discussed, people from all over felt honored to present their research. I remember sitting in the back and trying to follow the speaker, and there would be questions often interrupting the talk. Often O. A. would ask questions, sometimes very basic, and these would be the most revealing, the most teachable moments. I've learned to appreciate them more the older I become.

NR: During the war years 1941-1945, having to leave Leningrad (because of exhaustion and illness due to hard work digging trenches near Leningrad), O. A. taught school math first at an orphanage in the town of Gorodets (fall 1941-fall 1942), and then at her childhood school in her hometown of Kologriv. There she also gave free lessons to pupils willing to learn more. A mother of one of her students was so grateful that she managed to arrange an invitation from Moscow State University (MGU) for Olga to go study there and even have a Stalin's stipend (without which it would be impossible to survive).

LK: O. A. once told me that when she was a student in Moscow she (like many others) was always hungry. And sometimes she would sleep on a bench in the auditorium (there are benches, not chairs; the benches where students sit during the lectures have in front wooden panels with a sill-like desk shelf. The panels would protect a person sleeping on the bench from being seen by somebody standing at a lower level). For a pillow O. A. would use the textbooks she was studying. And she told me that she thought she even learned this way, by osmosis. And she practiced this technique in her later years by putting a book or a paper she wanted to understand under her pillow and sleeping over it.

NR: O. A. taught mathematics all her life. In Leningrad, from 1949 on, she taught first in the mathematics department, and then in the physics department of Leningrad State University (LGU). These were undergraduate classes, mostly PDEs (at the present time, at a Western university, those would be considered middle to senior graduate level), but she would talk about the current state of the art in PDEs and mention current open problems. Her textbook The Boundary Value Problems of Mathematical Physics, Springer edition, 1984, is an excellent exposition of her approach to PDEs. It is based on the course she had taught since 1949. (LK: I find this textbook still current and very useful and use it in my teaching.)

NR: I first met $\mathrm{O}$. A. when she was teaching boundary problems at the Mathematical Physics branch of the
Physics Department of LGU. Students called her "Grandma" Ladyzhenskaya, and she was one of our favorite professors. We liked her style, honesty, accessibility, and the clarity of her lectures, which were elegant, informative, and easy to follow.

LK: Once, when we discussed something and realized that the Egorov theorem would help on that particular occasion, O. A. said, "Wouldn't it be nice if theorems in textbooks were printed in color? Then Egorov's theorem could be printed in gold." "But Olga Aleksandrovna," I asked, "then what about the Newton-Leibniz formula?" I knew that the Newton-Leibniz formula was her favorite. "You are right, Lyova," O. A. said, "the Newton-Leibniz formula should be in gold. And Egorov's theorem-in silver."

O. A. was curious about many topics in and around mathematical physics. Sometimes, she would ask colleagues to make a presentation on the topic she was interested in at one of the seminars. Sometimes, she would ask them to explain a question to her.

NR: O. A. was always interested in new developments in mathematics and mathematical physics. On several occasions I had a chance to explain to her recent developments in mathematical aspects of quantum theory. Then came 1989, and I left for the United States.

We had a very nice reunion in Berkeley. She was visiting Stanford for two months at that time, and Craig Evans invited her to give a colloquium. She also was invited by the Noetherian Ring to give a short talk at a seminar that they frequently organized after the colloquium. When I drove her back to Stanford after the colloquium dinner she said that she was pleased to see this seminar and to talk to so many young women mathematicians. After a pause she added that those young people probably did not appreciate enough the wonderful life they had.

During perestroika and after, all of a sudden Soviet/ Russian people were free to travel abroad. Many scientists left for good, and that worried O. A. a lot. She was a patriot and cared very much about Russian culture and science.

LK: When I told O. A. in 1990 that I was going to Princeton the following year, she looked concerned: "Who is going to do math here? Please come back." But on the positive side, after a long ban on her travel to the West, $\mathrm{O}$. A. was allowed to travel. We kept in touch and would see each other be it in Kansas, or Iowa, or New York, every time O. A. was in the US. At the end of 2003, when I moved to Miami, O. A. was planning to visit Max Gunzburger at Florida State University in Tallahassee. I was going to arrange her visit to Miami. I talked to O. A. on the phone on January 11, 2004, the day before her departure. She was in good spirits, though complained a little about her eyes: "I have to use crayons for writing!" That night Olga Aleksandrovna quietly passed away in her sleep. 


\section{Darya Apushkinskaya and Alexander Nazarov}

Olga Alexandrovna Ladyzhenskaya was born on March 7, 1922 in the tiny town of Kologriv in the Kostroma region, five hundred kilometers northeast of Moscow. Early on Olga showed an aptitude for mathematics. Her father, a mathematics teacher and a former nobleman, was executed in 1937. Because of that Olga was considered to be the daughter of an "enemy of the people" and was not admitted to Leningrad University, despite getting excellent grades on the entrance exams. She studied at the Second Leningrad Pedagogical Institute. In 1941, after the beginning of the Great Patriotic War, Olga returned to Kologriv, where she taught mathematics in a secondary school.

In 1943, Ladyzhenskaya was admitted to Moscow University, and in 1947 she graduated with a diploma with honors (her supervisor was I. G. Petrovsky). After her marriage to A. A. Kiselev, she moved with him to Leningrad and attended graduate school at Leningrad University (her advisor was S. L. Sobolev). Ladyzhenskaya got her PhD in 1949. Soon afterwards, taking just two years, she wrote her Habilitation thesis, The Mixed Problem for a Hyperbolic Equation, where she justified the Fourier method for general second-order hyperbolic equations in the multidimensional case. However, she could only defend the thesis after Stalin's death in 1953.

Starting in 1950, O. A. worked at Leningrad University, where in 1955 she became a Full Professor. In 1954, she was named a Fellow of the Leningrad Branch of Steklov Institute (LOMI). In 1961, O. A. organized the Laboratory of Mathematical Physics in LOMI; she led the Laboratory until 1998.

Olga Alexandrovna Ladyzhenskaya published more than 250 articles and authored or coauthored seven monographs and a textbook:

1. The Mixed Problem for a Hyperbolic Equation, GTTI, Moscow, 1953 [Russian].

2. The Mathematical Theory of Viscous Incompressible Flow, Fizmatgiz, 1961 [Russian]; English transl., Gordon and Breach, New York, 1963.

3. Linear and Quasilinear Elliptic Equations (with N. N. Uraltseva), Nauka, Moscow, 1964 [Russian]; English transl., Academic Press, New York, 1968.

4. Linear and Quasilinear Equations of Parabolic Type (with V. A. Solonnikov and N. N. Uraltseva), Nauka, Moscow, 1967 [Russian]; English transl., Amer. Math. Soc., Providence, RI, 1968.

Darya Apushkinskaya is privat-dozentin at the Saarland University, Saarbruecken; professor of mathematics at the People's Friendship University of Russia (RUDN University); and Moscow Senior Researcher at the Chebyshev Laboratory, St. Petersburg State University. Her email address is darya@math.uni-sb.de.

Alexander Nazarov is leading researcher at the St. Petersburg Department of Steklov Mathematical Institute and professor at the Mathematics and Mechanics Faculty, St. Petersburg State University. His email address is a1.i1.nazarov@gmai1.com.
5. Mathematical Problems of the Dynamics of Viscous Incompressible Fluids, 2nd ed., revised and enlarged, Nauka, Moscow, 1970 [Russian].

6. Linear and Quasilinear Elliptic Equations (with N. N. Uraltseva), 2nd revised edition, Nauka, Moscow, 1973 [Russian].

7. Attractors for Semigroups and Evolution Equations, Lezioni Lincei, 1988; Cambridge Univ. Press, Cambridge, 1991.

8. The Boundary Value Problems of Mathematical Physics, Nauka, Moscow, 1973 [Russian]; English transl., Applied Mathematical Sciences, 49, Springer, New York, 1985.

Ladyzhenskaya's mathematical achievements were recognized in many ways: by the Leningrad University Prize (twice, in 1954 and 1961), the Chebyshev Prize of the USSR Academy of Sciences (1966), the State Prize of the USSR (1969), the Kovalevskaya Prize of the Russian Academy (1992), and the Ioffe Prize of the City of St. Petersburg (2002). In 1981, she became a Corresponding Member and, in 1990, a Full Member of the USSR Academy of Sciences. In 2002, she was awarded the highest award of the Russian Academy, the Great Gold Lomonosov Medal. She was elected a foreign member to the oldest German academy Leopoldina (1985), the Accademia Nazionale dei Lincei (1989), and the American Academy of Arts and Sciences (2001). She was also awarded the degree of Doctoris Honoris Causa by the University of Bonn (2002).

Her personal charm, her ability to spot talented students, her willingness to help beginners-all these qualities enabled Ladyzhenskaya to foster a whole pleiad of brilliant scientists, leaders of the renowned St. Petersburg school of partial differential equations and mathematical physics. Among them were Ludvig Faddeev, Nina Uraltseva, Vsevolod Solonnikov, and many other prominent mathematicians.

In 1947, together with V. I. Smirnov, O. A. organized a weekly seminar on mathematical physics, which is still meeting today. Almost all of the St. Petersburg experts on partial differential equations were or are participants in this seminar.

Ladyzhenskaya was a member of the St. Petersburg Mathematical Society since its revival in 1959. For many years she served as a board member, vice president, and from 1990 till 1998, the president of the Society. In 1998, she was elected an honorary member of the Society. In 2014, the Society established a scholarship named after O. A. Ladyzhenskaya.

In the second half of the 20th century Ladyzhenskaya set a new fashion in the theory of partial differential equations. She was a real strategist in mathematics, and was not only interested in solving problems, but, more importantly, in stating new problems and developing new approaches. She played an important role in developing the concept of a generalized solution. Important pioneering results in the spectral theory for differential operators, the diffraction 
theory, and the convergence of finite difference methods are associated with the name of Ladyzhenskaya. In the 1960s Olga Alexandrovna, together with N. N. Uraltseva, presented complete solutions to Hilbert's 19th and 20th problems for a wide class of second order PDEs.

It is not a secret that Olga Alexandrovna's main mathematical love was the theory of fluid dynamics. Her very influential book The Mathematical Theory of Viscous Incompressible Flow, published in 1961, was translated into many languages and has become a classic in the field. Up to this day, it continues to be an excellent introduction to the mathematical foundations of hydrodynamics.

Some of Olga Alexandrovna's achievements related to the mathematical theory of the Navier-Stokes equations will long be remembered. Among these is the great result on the global well-posedness for those equations in dimension 2, proved in the 1950s. As was shown in her joint work with A. A. Kiselev, a similar result is valid in dimension 3 as well, but holds only on a finite interval of time. It is worth mentioning that to this day the global well-posedness for the three-dimensional problem remains an open problem. Moreover, the issue of existence and uniqueness of physically reasonable solutions to the NSEs in three dimensions has been chosen as one of the seven Millennium million-dollar prize problems by the Clay Mathematics Institute.

Olga Alexandrovna also introduced the concept of attractor for two-dimensional Navier-Stokes systems and proved its existence. This opened a new chapter in the theory of evolutionary PDE, namely, the theory of stability in the large.

Olga Alexandrovna possessed a rare quality: the courage to express one's opinion. She reacted keenly to any injustice and misfortunes of others. In particular, she advocated time and again for the students who for political reasons had problems with being admitted to graduate school.

O. A. Ladyzhenskaya was an extraordinary person, deeply engaged in all aspects of life. She was an enthusiastic traveler, a skillful storyteller, and a person well versed in literature, arts, and music. Among her friends were famous poets, writers, musicians, and painters, in particular, Anna Akhmatova, Iosif Brodsky, Alexander Solzhenitsyn, and Boris Tishchenko. She was mentioned by Solzhenitsyn in his list of the 257 witnesses in the Gulag Archipelago, while Akhmatova dedicated to O. A. the poem "In Vyborg." After visiting Leningrad, the French mathematician J. Leray remarked that he saw the Hermitage, Peterhof, and Ladyzhenskaya.

See p. 432 for an announcement of the Ladyzhenskaya Medal in Mathematical Physics.

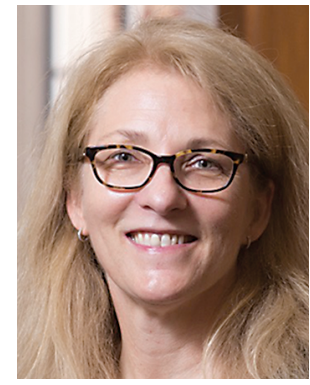

Della Dumbaugh

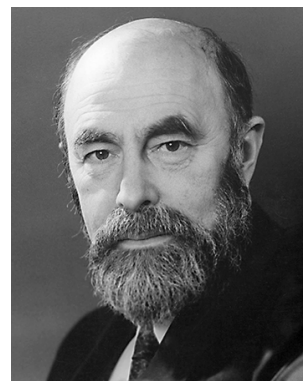

Anatoly Vershik

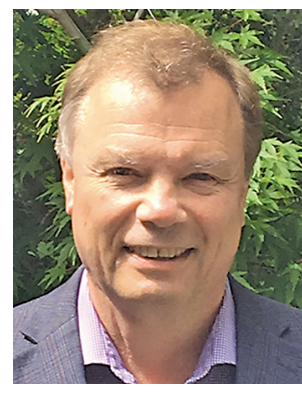

Nicolai Reshetikhin

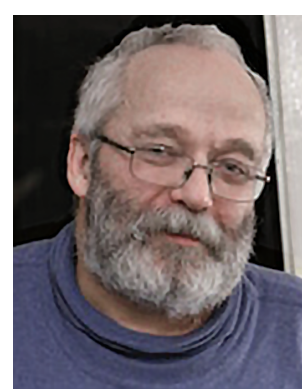

Alexander Nazarov

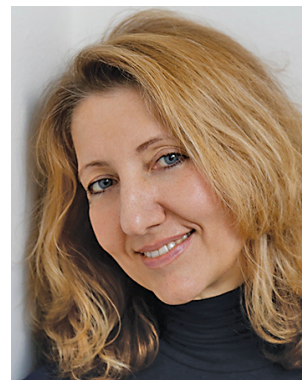

Panagiota Daskalopoulos

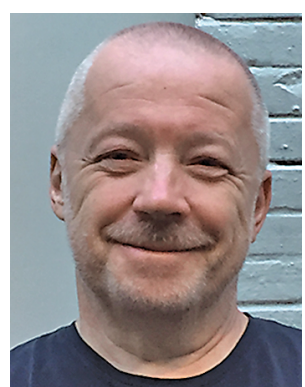

Lev Kapitanski

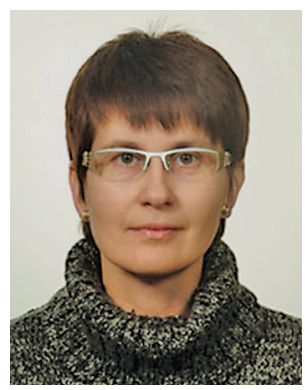

Darya Apushkinskaya

\section{Credits}

Figure 1 is courtesy of St. Petersburg Math Society.

Dumbaugh photo is used by permission of the University of Richmond.

Daskalopoulos photo is by Scott Mead.

Vershik photo is by Rita Vershik.

Kapitanski photo is by Mary E. Donworth.

Reshetikhin photo is by Antonina Staros.

Apushkinskaya photo is courtesy of Darya Apushkinskaya.

Nazarov photo is by Sophia Nazarova. 